\title{
Becoming Critical Communities of Practice in Pre-Kindergarten
}

\author{
Melissa Sherfinski \\ West Virginia University \\ Morgantown, $W V$
}

\begin{abstract}
Based on a case study of two West Virginia communities implementing state universal pre-kindergarten (UPK) policy, the lens of communities of practice (Lave \& Wenger, 1991) is used to consider the positions of low-income families within the reform and how institutional frameworks of home-school relations presently do and do not support them. A critical communities of practice (CCoP) orientation uses the knowledge and skills of families, educators, and children in the articulation and development of policies and practices that support critical, empowered stances toward learning. This article examines the gaps in present UPK practices and then suggests how CCoPs might be developed in this and similar settings to enhance home-school relationships.
\end{abstract}

\section{Introduction}

Critical scholarship has shown that families positioned outside the norm may feel unwelcome and underappreciated in schools, which limits trusting home-school relationships (Cooper, Riehl, \& Hasan, 2010; Li, 2010). At the same time, strong home-school relationships have positive effects on young children (Long, Souto-Manning, \& Vasquez, 2016). K-12 schooling is organized in a top-down, compliance-based fashion (Fuller, 2007), and family engagement at the universal pre-kindergarten (UPK) level may be prescriptive and oriented to the middle-class (Sherfinski, 2013). Unfortunately, "instead of insisting on professional development to help educators recognize inequities and then transform teaching to broaden its cultural, linguistic, and social foundations, district, state, and federal efforts typically are doubled to focus on the very practices that marginalized and underserved students to begin with" (Long et al., 2016, p. 10). Communities of practice, which are groups that work together to learn knowledgeable skills, are an important tool to address these gaps and concerns (Lave \& Wenger, 1991). The purpose of this case study research from West Virginia is to inform policy and practice regarding home-school relationships in pre-kindergarten settings by analyzing gaps in public pre- 
kindergarten home-school relations. Specifically, the research considers how critical communities of practice (CCoPs), consisting of educators and families, might become a viable opportunity for improving education at the pre-kindergarten level.

Recently there have been shifts in early childhood systems and demographic patterns that have altered diversity within classrooms (McCabe \& Sipple, 2011). UPK systems, for example, may include children of all income levels and (dis)abilities in the same classroom (Sherfinski, Weekley, \& Mathew, 2015). This may offer increased possibilities for authentically engaging anti-bias and critical multicultural education in order to reframe education away from standardized and neoliberal meanings of schooling (Brown \& Lee, 2012) and inform how young children and their families and educators learn to see one another and the world (Long et al., 2016). Anti-bias and critical multicultural education encompass the five strands of multiculturalism that Sleeter and Grant defined in 1988, which are: 1. educating the culturally different, 2. single-group studies, 3. human relations, 4. multicultural education celebrating a range of cultural differences, and 5. education that is multicultural and social reconstructionist. The most emphasis, however, is on the fifth strand (Ramsey, 2004). UPK and similar reforms offer spaces for anti-bias and critical multicultural education to take hold in order to address inequitable power relationships related to Whiteness and poverty, which were major issues in this research. However, elementary school principals, once only in charge of K-5 schools, have been repositioned as P-5 leaders, often without specific pre-kindergarten backgrounds. These leaders are rarely provided long-term professional development and may be cut off from decision-making at the state and national levels; meanwhile, educators are often not prepared in teacher education and professional development, nor by professional frameworks like Developmentally Appropriate Practices (DAP) (Copple \& Bredekamp, 2010), to address profiling of low-income and minority students and families and to address bias and pedagogical and structural inequalities that are likely to occur with students of diverse backgrounds (Long et al., 2016).

Furthermore, the language of schools can actually lock teachers into self-perpetuating discourses and values heavily influenced by specialization and neoliberalism that affect codes of practice (Fleer, 2003). Families and educators who do not know the languages of DAP and early childhood special education may find themselves excluded from the field as "not early childhood." This language game can be particularly difficult in UPK, which has many masters to serve and even those working within UPK have a challenging time negotiating the many languages spoken. For example, in this research, UPK teachers spoke of needing to be fluent in the languages of DAP, the Early Childhood Environmental Rating Scale (ECERS), the Classroom Assessment Scoring System (CLASS), Head Start requirements, kindergarten readiness, Early Learning Standards (ELS), and elementary success through college and career readiness, to name a few. These many discourses are difficult for educators to navigate and even more difficult for families. In this scenario, working toward truly democratic learning communities that support all children's development is challenging (Crozier \& Vincent, 2005). In this case, educators find it difficult to dialogue amongst themselves and with families, and families have difficulty articulating their concerns while adding to the knowledge and skills base. When home-school relationships are affected by White middle-class educators' deficit perspectives of low-income families and families of color, as was the case in this research, the results can be devastating because they contribute to inequities through strained relationships and diminished outcomes (Cooper et al., 2010). This becomes even more challenging when professional development systems reinforce deficit views, as was the case in this context. 
CCoPs are a departure from discontinuous home-school relations because educators and families participate in communal and critical learning together (Wenger, 2000). Because family engagement requires mutually determined agendas and shared decision-making, educators need to understand that families have important knowledge that should influence school reform (Hands, 2014). CCoPs may be a hopeful possibility for deepening dialogue among families and schools, especially important as systems are shifting and changing (Jozkowiak, Cahill, \& Theilheimer, 2016). While CCoPs might most easily be led by strong, social justice-oriented administrators whom in many places around the United States are women and men of color (Long et al., 2016), in the communities under study, administrators were all White and middle-class. The situation was made more challenging because there were few principal preparation programs available, and social justice was not the core of school leadership curricula, given a long-standing focus in the state on traditional education and control of student behaviors (Stack, 2016). In this paper, I describe and analyze a case of home-school relationships in UPK in order to consider how CCoPs might become an opportunity for positive change, exploring specifically: What are the experiences of low-income families in UPK? How do institutional contexts support home-school relationships among educators and low-income families, and how might CCoPs address these?

I set the stage for exploring the research questions by providing a conceptual background on CCoPs. While pre-kindergarten and UPK programs nationwide often share similar school readiness goals, there are also differences among state policies and local program structures. Therefore, I map the context of my case. After presenting the findings detailing home-school relationships for low-income families and educators and their institutional contexts, I discuss policy and practice recommendations stemming from the findings. While some of these are more pertinent to the Appalachian and UPK context in which the case is situated, many of the suggestions may benefit other pre-kindergarten programs.

\section{Conceptual Background}

This paper takes a critical and post-structural approach to understanding community members' experiences with UPK by listening to voices of families and educators through the lens of CCoPs (Wenger, 2000). The goal of specifically critical communities of practice is to help families and educators gain awareness of inequities and support them in drawing on new knowledge, relationships, and identities (Ladson-Billings, 2000; Myers, 2016; Oakes, Rogers, \& Lipton, 2006). This is a crucial place to confront colonizing practices in schools, such as lingering issues of DAP as they relate to difference (Long et al., 2016). For example, sometimes standards based on developmental theories do not support culturally-grounded thinking about education and child-rearing practices, and so in these cases families and schools may become pitted against one another rather than empowered. In these communities, teachers have a crucial role as leaders who understand and perform cultural work that addresses inequities (Cooper, 2009). This can be exacerbated in the Appalachian setting of this study because of long-time colonizing practices that affect the socio-cultural and historical context of the communities (Sherfinski, 2013; Sherfinski, Weekley, \& Mathew, 2015). While there can be an underlying assumption that overwhelmingly White communities do not need multicultural education, indeed they do (e.g., Derman-Sparks \& Ramsey, 2006). In Appalachia, multicultural education is essential because narratives of White racial homogenization and innocence have served to mask racial inequalities related to mining, logging, and other industries; furthermore, the media, color writers, and Northern missionaries have created and sustained the "hillbilly" characterization of Appalachia by engaging in class bias, objectification, and exclusion (Billings, Norman, \& Ledford, 2000). Thanks to these influences, 
addressing whiteness - or the ideology of how the cultural, historical, and social aspects of White identities construct privileges - has been very challenging in early childhood because of developmental prohibitions on what it is that young children must be protected from, in which arenas they may and may not speak, as well as the silencing of culture and difficult everyday realities in popular early childhood frameworks (MacNaughton, 1997; Saltmarsh \& Davies, 2010; Silin, 1995). While little research has connected the dots between Appalachian identities and early childhood education, indeed the context of power relations in Appalachia deeply affects education (Sherfinski, Weekley, \& Slocum, 2016). In this region, as in other places around the country and world, whiteness serves to fracture, fragment, mask, and otherwise obscure rich opportunities for home-school relationship-building (Derman-Sparks \& Ramsey, 2006), yet it can be deconstructed in CCoPs.

Communities of practice have been defined in many different ways. I go back to Lave and Wenger's original work (1991) for my definition, expanding it to a focus on critical multicultural knowledge that challenges whiteness. Lave and Wenger see communities of practice as a way to conceptualize learning within professional discourse communities, but also as a method of knowledge generation and dissemination. A CCoP is an intentional learning and social action site where diverse individuals come together to co-construct new knowledge and develop an extensive repertoire of activities, common stories, and ways of speaking and acting (Lave \& Wenger, 1991; Wenger, 1998). The participants grow to relate to one another and the broader world in new ways (Wenger, 1998). Resultantly, the learners develop new social identities and assume new roles in schools. CCoPs do not neatly demarcate learners' relationships, identities, and learning; instead, they conceptualize these qualities as being interconnected and part of a system of relations. This social theory of learning differs from more traditional theories that conceptualize learning as an individual process.

CCoPs bond groups and strengthen communities, developing mutual recognition as well as rich democratic potential (Apple \& Beane, 2007). They are especially concerned with who is responsible for generating and sharing knowledge and with whom; they are about diverse individuals in a school community embracing each other as teachers and learners. Educators confront their own biases about families' abilities to participate actively in decision-making (Hands, 2014). This can be done specifically by blurring boundaries among the roles of families, children, educators, and school leaders through teacher education, professional development, and collaborative dialogic work (Miller, 2005). The important shift from top-down leadership is that the voices of underrepresented groups become increasingly included in collaborative inquiry, and the barriers to such inclusion are collectively examined and reconceptualized by creating new transgressive and transformative opportunities for participation (Buysse, Sparkman, \& Wesley, 2003). CCoPs help learners gain awareness of inequities and then support them in drawing on their new knowledge, relationships, and identities to make their communities, institutions, and social systems more democratic and socially just (Oakes, Rogers, \& Lipton, 2006).

Flourishing home-school relationships can be cultivated in CCoPs by developing experiences, stories, tools, and ways of addressing common problems around things that matter (Wenger, 2000). Part of this process is questioning and confronting policies and practices that may not be fully emancipatory. For example, abstract ideas need to be reified, or made concrete, if they are to be understood and used as tools in communities (Wenger, 1998). For example, "child-centeredness" has been reified in early childhood education such that it has resulted in simple slogans like "all children learn through play." Terms like "child-centeredness" then become embedded universally and unreflectively. For example, in thinking about children 
learning through play, it is crucial to consider what sort of play and what sort of learning is being discussed in context in order to be critically reflective (Fleer, 2003). CCoPs are powerful because they have the potential to deconstruct reified knowledge about play and other critical concerns like poverty and culture.

As individuals spend time in CCoPs they move from peripheral participation at the margins to seeing themselves as members, becoming central figures in dialogue about issues crucial to the school community (Lave \& Wenger, 1991). This practice-centered approach to human learning challenges the validity of interpreting professional practices on the basis of prescribed codes and structures (e.g, DAP), instead focusing on individuals' real contributions to the social order (Buysse et al., 2003). This is a shift from teachers employing "best practices" to communities working things out in process. CCoPs are an important lens for thinking about goals and processes that might support children's and families' experiences (e.g., Hong, 2011). Oftentimes, while parents are discussed as being "good" or "bad" school parents based on their involvement in supporting middle-class school values as promoted by national, state, and local policies and practices (Crozier \& Vincent, 2005), the possibility of diverse families and educators sharing power together in more mutually informed decision-making is masked or ignored while various administrators and educators struggle for power in educational decision-making, and families and children are left behind. Sometimes it may feel to people that their lives are so far removed from what is needed to change, that what happens in a CCoP meeting and what is possible in reality are not always the same (Miller, 2005). Cultural and historical baggage affects everyone's ability to participate in groups (Hodges, 1998; Lawrence-Lightfoot, 2004). While not often discussed in $\mathrm{CCoP}$ theory, it is important to raise the possibility of difference instead of denying it as part of the group process.

From a school leadership perspective, a vision and plan for change that is focused on social justice, rather than kowtowing to mandates and compliance issues, is critical (Long et. al., 2016). In this framework, the key is using policy to innovatively break away from monocultural standards. Social justice principals do a number of things to support CCoPs such as: (1) They recognize inequities and discriminatory acts; (2) engage critically in institutional and self-examination; (3) listen to children, teachers, and families and use these insights to disrupt monocultural practices; (4) work with teachers as partners to identify oppressive practices and change them; (5) recognize and embrace family expertise and knowledge; (6) advocate for children; and (7) promote innovation within their constraints while seeking to change the system (Long et al., 2016). However, in the case of UPK, where there are multiple administrators and policy discourses shaping pre-kindergarten practices and, as mentioned, a dearth of critical preparation, diffuse messages may be a barrier to developing CCoPs. A lack of formal education and professional development in critical multicultural education through area colleges, universities, and school districts contributes to the difficulties in $\mathrm{CCoPs}$, although with multiple administrators, there may be a greater chance of having someone available with a responsive administrative presence even if they are not the building principal.

Given that there were no social justice-oriented administrators in the communities under study, I want to take a more pragmatic approach to framing CCoPs. Although school leadership is often seen as the place from which CCoPs can develop and grow, there are other possibilities (Claxton \& Carr, 2004). For example, teacher education programs can contribute to CCoPs when teacher educators have knowledge of critical multicultural education and help others to critically interrogate whiteness as it is embedded in policies and practices (Hands, 2014). CCoPs may be created on a smaller scale, for example by pre-kindergarten and kindergarten teachers and families 
coming together and working with one or more teacher educators and/or administrators. When the interest for creating CCoPs comes from below, there may need to be innovation in the $\mathrm{CCoP}$ structure itself. Keeping these ideas in mind, I want to consider how a rhizomatic assemblage, meaning "an uncentered growth, a multiplicity, characterized by connection and heterogeneity...constantly producing shoots and rootlets" (Deleuze \& Guattari, 1987, p. 7), might shape CCoPs in organic ways coming not only from above through the school principal, but through all the educators and families in the community under study. In some UPK and other prekindergarten contexts, this kind of poststructuralist approach to CCoPs can be seen as a way not to by-pass principal leadership, but to offer hope and possibilities for action in places where there are not strong, critically-oriented leaders of the type that Long and her colleagues speak, and currently no systematic mechanism to produce them.

\section{Study Background}

\section{UPK Definition}

West Virginia UPK is readiness-oriented in its focus on instruction/assessment preparatory for kindergarten and elementary school success. Although unfortunately there are many children and families who are still unserved or underserved, pre-kindergarten has expanded tremendously in the U.S. of late, with 40 states and more than 1.2 million children now participating in prekindergarten at the age of four (Barnett et al., 2015). New developments like UPK have been a means to pre-kindergarten expansion. The delivery of pre-kindergarten programs is no longer targeted to only low-income and minority children, as in Head Start. UPK is a relatively new reform in early childhood that might offer increased opportunities for families to become active participants in education. It is implemented in nine states and the District of Columbia (de la Torre et al., 2011). UPK is designed to meet the needs of all children, including the struggling middleclass eager to find affordable pre-kindergarten opportunities (Schulman \& Barnett, 2005). In contrast, the much more widespread targeted pre-kindergarten programs provide education to lowincome, minority, and special needs students only. Public support for the UPK reform has come in large part from those middle-class families struggling to find high quality pre-kindergarten for their children (Gormley, 2005). UPK has several documented benefits. It boosts cognition for all children, and especially poor and minority children (Gormley \& Gayer, 2005; Gormley et al., 2008). UPK also has been linked to supporting language development for low-income students (e.g., Henry \& Rickman, 2007; Mashburn, Justice, Downer, \& Pianta, 2009).

\section{UPK in West Virginia}

West Virginia Policy 2525 ("Universal Pre-K Law") lays the groundwork for UPK practices. The West Virginia Early Learning Standards (WVBOE, 2015) support the educational needs of children in the program (WVBOE, 2014). The law pays attention to inclusive environments, family engagement, and approved curriculum as key elements of the reform. The free, part-time pre-kindergarten program is voluntary in that families may choose whether or not to send their children.

The reform emerged from high-level legislation (Bushouse, 2010), and individual counties have worked to develop programming to respond to the policy directives. West Virginia's UPK was rolled out in 2003 and fully implemented starting in 2012-2013. During this period, enrollment of four-year-olds grew substantially, with $51 \%$ of children served by UPK/Head Start/Special Education in 2003 (Barnett et al., 2003) and 72\% served in 2015 (Barnett et al., 2015). 
In 2014-2015, a total of 15,256 children were enrolled in 990 UPK classrooms; one-third of these are Head Start-funded students, and one-fourth have IEPs (WVDOE, 2015a).

Children from racial/ethnic minority groups are a small but growing fraction of UPK attendees statewide; their attendance rates were just two percentage points above that of young children as a whole (Cavalluzzo et al., 2009). In West Virginia in 2014-2015, of 279,899 total students P-12, the racial make-up of the schools was 91\% White, 5\% African American, 2\% Hispanic, 2\% Multi-racial and 1\% Asian (WVDOE, 2015b). In West Virginia in 2006/2007 the UPK attendance rate was $45 \%$ for minorities and $43 \%$ for all children (Cavalluzzo et al., 2009). In that same year, children with IEPs had the highest attendance rate, at $49 \%$. Rural counties had much higher overall participation rates at $49 \%$ compared to $35 \%$ in non-rural counties. Children qualifying for free and reduced price lunch attended at lower rates than those of families from the higher income brackets, at only $37 \%$. While the statistics represent improved access over the years for all sub-groups, large numbers of low-income children in West Virginia still are not attending pre-kindergarten.

According to the state policy, family engagement requirements for teachers include two documented face-to-face conferences each year, recommended to be home visits. Additional required components of family engagement include, at a minimum: documenting communication with parents, such as through newsletters, phone calls and email; necessary transition services into and out of the program; ELL services; special education services; and open classrooms in which families are invited in and encouraged to participate (WVBOE, 2014).

Public schools and UPK administration are organized at the county level in the state of West Virginia. Therefore this case is bounded within two counties in order to capture practices in two unique regions in the state: Mayville is a Northern globalizing county with some industry, hospitals and a small city as well as rural mining areas; whereas Topton is a rural, extremely mountainous Southern county with a rich history of mining and logging.

Among the counties in 2014-2015, children's participation rates ranged from 55\% to $100 \%$, with the state average at $76 \%$. The participation rate is the percentage of children who attended kindergarten in 2014-2015 who also attended UPK.

There is a maximum class size of 20 and 1:10 ratio required in all UPK classrooms.

All teachers must spend 15 clock hours annually in professional development activities, which are sponsored by the state. Public school and collaborative sites both require the teachers to hold Bachelor's Degrees, but there are differences in the precise type of early childhood-related certification needed depending on the type of school site (WVDOE, 2015a).

The 2015 Early Learning Standards Framework (WVBOE, 2015), released to teachers during the 2015-2016 phase of data collection for this research, contains standards for foreign language acquisition, cultural awareness, and the integration of the child's home language into the classroom. The West Virginia Center for Professional Development, associated with the State Department of Education, has for years provided training on Ruby Payne's (2013) "culture of poverty" framework, available to new teachers in the state, and has recently extended this to a "teacher academy" that is open to long-time teachers as well (http://www.wvcpd.org/cmswiki.aspx?name=teacheracademyprogrampage). The culture of poverty framework espoused by Payne has been strongly criticized by scholars for its lack of research basis and stereotyping of poor families (e.g., Bomer, Dworin, May, \& Semingson, 2008), but remains popular in rural Appalachia (Howley, Howley, Howley, \& Howley, 2014) and in the communities under study. 


\section{Mayville County Schools}

Mayville (a pseudonym) was chosen as the target county because it is a vibrant, diverse community experiencing the transition to UPK. It includes both very rural and suburban-type areas. The population of Mayville is approximately 60,000 residents. The racial makeup of the county is $91 \%$ White with Middle Eastern, Black, and Asian minority populations. Like the state of West Virginia itself, the community experiences high levels of poverty: $23 \%$ compared to the national average of $15 \%$, and $39 \%$ of the population have a college degree, quite a high level for the state and slightly higher than the national average (U.S. Census, 2010). The county is both suburban and rural, and the poorest families live in the rural outskirts.

According to the WVDOE (2015a), 174 Mayville four-year-olds and 33 three-year-olds in UPK received funding from Head Start, and 72 had IEPs in 2014-2015. The total number of UPK students that year was estimated to be 637 . The UPK participation rate is $80 \%$, slightly higher than the state average. The high rate is surprising given that there are many non-UPK choices for the middle and upper middle-classes (Cavalluzzo et al., 2009). The UPK students were divided among 11 public elementary school and 11 private preschool/childcare collaborative sites at the time of this writing.

\section{Topton County Schools}

Topton County was chosen because of its rural character and rich cultural history of mining and logging that is representative of many other regions of the state. The county is very large and mountainous, which poses challenges for transportation. There still remain P-12 schools and 2room elementary schools in the more remote regions.

The poverty rate in Topton County is $21 \%$, comparable to that of Mayville; however, the college graduation level is much lower at $18 \%$ (U.S. Census, 2010). The population was $97 \%$ White, with a small African American minority. As mining stagnates in this region, the fathers of young children are lured to board at gas fracking sites across the state during the week and return home to the family during the weekends.

In Topton County, 84 four-year-olds and 2 three-year-olds received funding from Head Start, and 31 had IEPs in 2013-2014 (WVDOE, 2015a). The total number of UPK students in 2015 was 205. The participation rate in UPK was 74\%, slightly below Mayville County and the state average. There were 13 collaborative UPK sites in 2015-2016, the vast majority situated in public elementary schools. A difference from Mayville County is that in Topton, there are typically one UPK classroom per school site, whereas in Mayville it was more likely for there to be 2-4 classrooms in each public school setting.

\section{Methodology}

The case study approach is often used to connect and examine many data sources, including interviews, observations, and artifacts (Stake, 2005). This case study is longitudinal, occurring in three phases that emerged as new questions developed. The longitudinal approach is powerful in that it allows me to study how UPK was being interpreted and enacted by teachers, administrators, and families as they became more familiar with the new policy. This research has been approved by my university institutional review board (IRB). Pseudonyms replace people/place names and I mask participant characteristics that are not essential to the analysis in order to better ensure confidentiality. 
I have been studying UPK practices in West Virginia since 2011-2012, when I performed an initial case study of UPK in West Virginia. In a follow-up interview study done in 2015, I spent several months interviewing UPK teachers (nearly all White, middle-class) to get a representative view of practices $(n=16)$, and then from this group I selected 3 teachers at 3 different schools in Mayville County and 2 teachers at 2 different schools in Topton County to follow for a year using ethnographic methods. The selected teachers were approved by their principals as solid teachers. I selected the counties to show variation in state contexts and selected the participants purposefully to represent each county's demographics, with county minority groups explicitly represented.

I interviewed the 5 selected teachers 3 times each $(n=15)$, as well as their administrators $(n=5)$, and diverse families from each teacher's classroom $(n=8)$. In addition, I interviewed a broader sample of UPK families from the counties $(n=28)$. Interviews $(n=72$ total) lasted on average 45 minutes. They included common questions about home-school relationships, school community building and climate for administrators, educators and families, as well as questions specific to each group's unique experiences. Interviews were audiotaped and professionally transcribed verbatim.

Throughout the 2015-2016 academic year I observed classroom and school practices including informal/formal home-school relationship-oriented activities, for a total of 189 observation hours. Field notes were written within 24 hours of the site visit (Emerson, Fretz, \& Shaw, 2011). Table 1 below summarizes the data analyzed for the study.

Table 1. Data collection.

\begin{tabular}{|c|l|l|l|}
\hline Timeline & $\begin{array}{l}\text { Phase 1: } \\
\text { Fall 2011-Fall 2012 }\end{array}$ & $\begin{array}{l}\text { Phase 2: Spring } \\
\mathbf{2 0 1 5}\end{array}$ & $\begin{array}{l}\text { Phase 3: } \\
\mathbf{2 0 1 5 - 2 0 1 6} \\
\text { Academic Year }\end{array}$ \\
\hline Interviews & $\begin{array}{l}\text { 28 parents, 8 teachers, } \\
\text { administrators }\end{array}$ & 16 teachers & $\begin{array}{l}\text { 8 parents, 5 teachers } \\
\text { (3 interviews each), } \\
5 \text { administrators }\end{array}$ \\
\hline Observations & $\begin{array}{l}\text { 1-2 half-day observations of } 8 \\
\text { teachers and schools, focusing } \\
\text { on classroom practices }\end{array}$ & $\begin{array}{l}7-9 \text { full-day } \\
\text { observations each of } \\
5 \text { teachers, focusing } \\
\text { on classroom } \\
\text { practices and their } \\
\text { school and home- } \\
\text { school relations } \\
\text { activities }\end{array}$ \\
\hline \multirow{5}{*}{ Artifacts } & $\begin{array}{l}\text { Documents related to policies, } \\
\text { programs, events, scheduling, } \\
\text { notes and journals about } \\
\text { navigating pre- } \\
\text { kindergarten/childcare services }\end{array}$ & & $\begin{array}{l}\text { Documents related } \\
\text { to policies, } \\
\text { programs, events } \\
\text { and scheduling }\end{array}$ \\
\hline
\end{tabular}

Because my research questions focused on the role of poverty in UPK and CCoP development, I included information from mainly the highest poverty contexts for this case, which were Milton and Viewpoint schools in Mayville County, and Pleasant Day and Mountaintop 
schools in Topton County. I read each interview transcript and the field notes and artifacts multiple times and did open coding on the documents. I compared families', administrators', and teachers' themes found in the interviews to every other one to see the similarities, differences, and tensions within each of those three groups (Stake, 2005). In addition, I compared teachers' and parents' interviews from the same schools along with the field notes. This triangulation allowed me to understand the areas of mutual agreement among participants and the complicated viewpoints present.

Memos facilitated the integration of emerging themes and findings. The most robust themes were: (1) trust and possibilities in home-school relationships for low-income families, (2) an institutional multicultural knowledge gap, and (3) lingering effects of Ruby Payne's "culture of poverty" discourses. In the findings section below, I present the themes.

\section{Findings}

Following the $\mathrm{CCoP}$ framework, administrators, teachers, paraprofessionals, families, and children along with university partners might come together to examine reified (objectified) knowledge common within the community so that they might re-interpret and act in the service of positive social change. In so doing, CCoPs are an opportunity to de-standardize pre-kindergarten initiatives, shaping home-school relations, curriculum, and pedagogy in ways that are culturally responsive to communities. In the findings section that follows, I outline how institutional contexts did and did not support home-school relationships for low-income families, and then I consider how gaps in multicultural knowledge affected possibilities for CCoPs to form and develop. Later, in the discussion and conclusion, I consider how this knowledge of contexts opens up rhizomatic spaces for CCoPs to take hold.

\section{Experiences of Low-Income Families}

The low-income families in the study experienced high levels of confusion around navigating the complicated UPK system in which Head Start is embedded, and in nearly all cases families focused on the emotional needs of their children in the transition to school, as in this representative comment from a mother:

"And I'm scared for Head Start. I am. But I need to give it a chance. Maybe not go by everybody's word and see for myself. Because my son will let me know if it's not making him happy. He'll cry, he cries any time we go anywhere that he doesn't want to be." (Ms. Myles, parent)

This data connects to what Reay and Ball (1997) have highlighted regarding working-class parents' emotions and decision-making related to schooling: "Far from being ill-considered, this reluctance represents a powerful common-sense logic in which to refuse to choose what is not permitted offers a preferable option to choices which contain the risk of humiliation and rejection" (p. 91).

Across my data, issues of trust between home and school had the potential to prevent families from entering UPK, to prevent them from feeling a welcome part of UPK, and to hold them back from becoming empowered leaders in a community of practice. However, family narratives such as these hold much potential. For example, helping all families work through issues related to (dis)continuities between home and school might best be supported by families 
who have "been there" already; indeed, Ms. Myles' worries could be a future strength if she were supported in entering and integrating into UPK and then eventually reaching out to other families who had similar experiences. In this way, following the $\mathrm{CCoP}$ as a rhizome of potential family empowerment, emerging anxieties about school might be a source of new "shoots" for strengthening equitable relations in the school community (Deleuze \& Guattari, 1987).

\section{An Institutional Multicultural Knowledge Gap}

Elementary principals were interested in establishing particular "brands" for their P-5 schools that served to distinguish themselves: "good character," "garden-based learning," "technological futures," and "environmental sustainability." This approach socialized families while in many cases it created barriers to genuine engagement. For example, Milton School provided many opportunities for families to learn the rules of their "lighthouse" approach to good character so that not only the children but parents could have their morals strengthened. As the principal told me, "We've found these [values taught in their lighthouse program] to be universal...basic tenants that everyone can agree on, so we start teaching those in Pre-K...." In contrast, a critical CCoP approach would begin with the dilemmas and concerns of the families and children and connect with systemic inequities. In Topton County, an elementary webpage welcomed families by announcing a technologically-driven school with several corporate sponsors; the next page on school policies described prohibitions about medications, limits on family visits to the school, strict attendance and late arrival instructions, and grade level promotion policies. To pass kindergarten, the children needed to recognize all numbers 1-20, count accurately to 50, and identify 23 of 26 capital and lowercase letters as well as sounds.

Overall, the educators I spoke with did not find the professional development (PD) contexts of their counties ideal. Currently, offerings were piecemeal and focused on areas such as policy dissemination and child abuse prevention (in Topton) and a smattering of themes as well as oneon-one work with instructional coaches if needed (in Mayville). There was an interesting neoliberal influence shaping the PD context of Mayville. A local school partner, for example, received a prevention grant to implement a social-emotional curriculum at the UPK level and so that became one of the PD highlights of the year. Whereas social networks influenced the PD context, neither of the county administrators saw the need for PD on multicultural education because each school identified as a unique cultural body with the principals and teachers giving their "own" children and families what they specifically needed. However, as noted above, school leaders were unclear about what culturally relevant and responsive teaching meant and focused on creating that identity rather than CCoPs. There was, in fact, an administrative "hot potato" between county UPK leaders and building principals; shifting the responsibility for serious conversation about culture to-and-fro served to silence critical attention to concerns regarding culturally responsive and relevant education.

Professional learning communities (PLCs) for teachers were emerging in both communities studied. Mayville County has started PLCs a few years before with the state push toward Common Core Standards. Their vertical teams were charged with unpacking the new Common Core Standards K-5, but UPK was originally excused from this work because their Early Learning Standards were seen as simpler and somewhat disconnected from the Common Core. In the past year, thought had shifted. UPK and K teachers were paired together in vertical PLCs to discuss their different standards in order to create a more seamless bridge between the grade levels. This was sometimes seen as challenging because Kindergarten was thought of as "worksheet-y" by UPK teachers and families even though the Early Childhood Coordinator for the county was 
pushing for Kindergarten to become more like UPK. In Topton County, PLCs would be first instituted in the upcoming academic year. In one case, the Topton UPK teacher felt good about this as she saw the Kindergarten teacher as very "whole child, developmental" like herself, whereas in the other school the UPK teacher dreaded the idea of vertical teams as she saw the Kindergarten teacher "not understanding" her curriculum and approach.

Social justice and culturally relevant and responsive education was not mentioned by individuals involved in the PLCs. That is in part because the focus of these groups was dictated by school leadership or outside consultants and focused on identifying bits of knowledge and processes for teaching various content areas/domains in the service of the neoliberal testing regime.

The focus on preparing children to meet academic pressures served to label learning communities as needing only educator expertise and left families out. However, fears of early intervention programs like UPK "not working" for all families served to split families into two groups in educators' minds - those who were simply surviving and could not be partners and contributors to education and their children's development, and those middle-class parents who were seen as just having "turned the corner" in thinking about UPK as education in which they should be involved, rather than daycare. This splitting was served by county policies that specifically barred low-income families from being engaged. In Topton, police background checks and classes on volunteering were required for families before they could be involved in the classroom in sustained ways. According to teacher Mrs. Fields, access to these structures was very difficult for low-income families, especially those in rural areas who had to travel upwards of an hour during daytime business hours to access checks and classes.

On the other hand, in Mayville County, the idea was that "if you could get one rural family member on board, they all would be on board." One rural school had a program called "Young "Uns" (a pseudonym) that included all children in the attendance area in special school events from birth so that children and families felt at home in the school community by the time they started UPK. These types of programs are like rootlets, linking to potential CCoPs because of the relationships already established among children, families, teachers, and administrators.

In sum, while there were opportunities like Young 'Uns, institutional barriers currently prohibited work on building authentic relationships between homes and schools in order to deepen and diversify knowledge production. For these reasons, PLCs and current home-school relations contexts were not necessarily easy segues into critical CCoP work.

\section{Ghosts of Ruby Payne}

The professional development context of the state and county promoted discourses of the "culture of poverty" (Payne, 2013). Many of the older generation of teachers and administrators had Ruby Payne training and as mentioned, some of the new hires had taken it through the state's professional development offerings. Educators justified their ideas related to class and race relations through the culture of poverty framework. In this sense and in the absence of alternative research-based critical PD, lingering ideas from Ruby Payne trainings and readings wafted through theory and practices in local schools. At the same time, Mayville County used its demographic diversity (consisting of mostly rural White schools, two schools with a higher ELL population, and two schools with a higher percentage of Blacks attending) to justify silencing PD and teacher education on critical multiculturalism because only the schools with relatively high levels of racial/ethnic diversity were seen to be appropriate candidates for knowledge about diversity. Payne's framework casts a deficit perspective on poor, working class, and minority families like 
Ms. Myles' highlighted above (Bomer et al., 2008). Teachers incorporated it into their homeschool relationship lenses:

"I myself had Ruby Payne... I recommend it to a lot of people because when you're White middle-class you don't understand why other people make the choices that they do.... So I found it to be helpful... Now it makes sense why I go on home visits and they [lowincome families] drive nicer cars than me." (Mrs. Coyne, Milton UPK Teacher)

The "culture of poverty" lens serves to reify low-income families as a homogenous, vulnerable, near-sighted group in need of consuming the self-regulation, morals, and homemonitoring techniques developed in UPK and P-5 schooling. Mrs. Coyne's response was common among many educators. It reflects the deficit view of individuals living in poverty that is common among middle- and upper-middle-class community residents and explicitly reinforced in Ruby Payne's professional development (see also Bomer et al., 2008). Mrs. Boyer (Westlake UPK Teacher) had a different spin in that she said that understanding generational poverty helped her not make judgements about families, that she could contextualize family discipline styles within the "culture of poverty" and thus not become inflamed when she heard negative reports about families because "they were simply living out their culture." This theme of downplaying "cultural" differences was also seen in the several teachers who lowered their voices and whispered when they were discussing poverty, similar to ways in which pervasive colorblindness provokes individuals to silence race (Pollock, 2005).

Teachers did have positive ideas about families as well. They saw family strengths as families' European-style housing compounds and close generational ties, turn-of-the-century traditions, and "a kind of mountain culture" in the most rural locales.

The deficit perspective on families, however, was deep and pervasive within both of these communities, many viewing families as not being ready for school involvement, "with ZERO experiences...[only] home with mom or grandma and [no] socialization," (Mrs. Castro, Milton Administrator). A perceived knowledge barrier prevented dialogue between home and school. For example, in Topton, teachers reported that when asked what goals they had for their children at home visits and conferences, low-income parents would say, "What you have sounds good," or "What did the other families say?" Topton teachers met together and decided to prime parents to say "school readiness" for their answer to this question. In seeing parents as unready to supply answers, the readiness orientation of UPK policy was strengthened and its official school-based definition strengthened. What was not considered in this scenario is that in the rural schools of Topton, families have lived among one another for generations and each small class of students remains together P-12; with one class per grade level, there is no room for separating individuals who do not get along. In this community, it is crucial that families are mindful of one another's wishes; it is not the case that the families do not have hopes, dreams, and ideas about what their children need. And it is also not the case that children and their families cannot contribute to these conversations. Although a mismatch between local culture and universalized school knowledge can cause families to be silenced, changing practice to a mutual dialogue over time, not boxed into a 20-minute conference or single home visit, would reposition families in an educational dialogue (see Hodges, 1998).

In Topton, the UPK teacher was seen as the expert on poverty in the building, because she was the only one who did a home visit to each child's residence. Guidance counselors conferred with UPK teachers to retrieve family information. In this way, UPK teachers were seen as "cultural 
brokers" to the low-income community (Delgado-Gaitan, 2001). Cultural knowledge was seen as embodied by these knowing UPK teachers, not something to be continually learned and reflected upon by the broader community. Alternatively, a poststructuralist view might create a space for understanding and including families through CCoPs to re-vision and redistribute knowledge and knowledge production.

Although teachers and administrators believed in Ruby Payne's teaching, they also were open to learning new ideas. Mrs. Coyne in Mayville County, although she had some strong "culture of poverty" beliefs, had a good point when she said, "we do kids a disservice by teaching in only White, middle-class ways," and Mrs. Talbott said that in Topton, she chose hope as a resource, believing that UPK could open the door to future progress and success for low-income children. She believed that instead of judging and viewing children and families as deficient, it was better to stop, reflect, and attempt to "walk in other people's shoes." Furthermore, when I explained culturally relevant and responsive teaching, which most had never heard of, they were genuinely interested in learning more. Teachers and administrators in many cases viewed themselves and their schools as rootlets, wanting to reconceptualize their knowledge and deepen their understandings (Deleuze \& Guattari, 1987). They believed that although they taught in unique schools, that it was important to learn and collaborate more with colleagues around the county, particularly as the context of diversity was changing. Because CCoPs are decentered unities that tolerate flux, they might be a useful structure to begin to address equitable education for the many low-income families in these communities.

\section{Implications and Conclusion}

This work with the communities is ongoing. I suggest a number of ways that educators including myself and my university colleagues might be open to shoots and rootlets, working towards creating CCoPs that do not necessarily require the school principal to be the primary leader, in order to address the multiple character of leadership and practice in UPK communities and the challenges of UPK integration within formerly K-5 elementary schools. Also important to consider are the historical silences around critical multiculturalism and whiteness in many Appalachian communities. Addressing these embedded ideas would necessitate cultivating educators and families who can define a vision, work to understand (in)equities, engage in thoughtful advocacy, and make sure that families' and children's voices are heard and acted upon. It would also involve recognizing that even "White" schools need to address inequities and engage in critical multicultural education, which will benefit all children and families. These ideas can serve as action steps for dismantling the current discourses and inequitable conditions that exist in UPK and P-5 school communities.

There are a number of action steps that make sense for these communities. The steps take into account the specific possibilities and constraints of the UPK context and the Appalachian cultural context; however, many of these ideas might be adapted to other pre-kindergarten settings in which cultural of poverty discourses and a weak structure of social justice leadership and professional development are a persistent hindrance to forming and sustaining CCoPs. These are the recommended policy and practice changes as I see them. I suggest them as ideas and inspiration to be used fluidly in regard to local contexts:

(1) Recognize the impact of culture of poverty discourses on the capacity for critical multiculturalism within communities. In many cases, culture of poverty discourses may be long-standing and normalized so that their origins have become unclear. The 
discourses of poverty should be reified and deconstructed systematically through teacher education and professional development. This work must be done by both administrators and teachers, in collaboration with local teacher educators and professional development specialists. It is important to specifically include the UPK teachers who historically have been excluded from K-5 professional development activities. As shown in the findings, in rural schools UPK teachers may be the only liaisons in the school building to family homes. They may have important training and knowledge to share with the rest of the elementary school faculty. Because discourses of child innocence and protection perpetuated in early childhood and elementary programs can serve to bolster the deficit view of low-income children and families and be hindrances to learning critical multicultural knowledge, it is important to become familiar with theory and research that supports critical knowledge construction. There are specific texts that can be used by P-5 educators, teacher educators, and professional development specialists to unlearn the culture of poverty stance by using research to help examine the meanings of "culture," "poverty," and "family resilience." Gorski's (2013) book Reaching and Teaching Children in Poverty is a text that we are using effectively through West Virginia University's early childhood and elementary education programs and spreading into P-5 networks. Another important text, given the communities' silencing the need for anti-bias education in White schools, is Derman-Sparks and Ramsey's (2006) text, What if All the Kids Are White: Anti-bias Multicultural Education with Young Children and Families.

(2) Investigate how complex administrative and program structures, such as those created among UPK and K-5 education, might serve to constrain yet also potentially open up possibilities for CCoPs. In this study, what I called administrative "hot potato" served to silence culturally responsive practices and was a barrier to critical practices forming in a systematic way. While there was agency from below towards culturally responsive practices, there is room for growth and innovation in this area. For example, UPK administrators (rather than only building principals) may conceivably bring knowledge and experience that could be used to leverage and enhance CCoPs.

(3) Examine how PLCs and CCoPs may compete for busy teachers' time. Creatively negotiating a dedicated space for $\mathrm{CCoP}$ work and understanding the differences between the two groups is crucial for their sustainability.

(4) Consider the relationships between teacher education, professional development, and CCoPs. In Appalachian communities where there may be very few individuals with knowledge of critical multiculturalism, it would be important to include individuals with this expertise while ensuring that a dialogue is cultivated in order to examine community discourses and norms.

(5) Embark upon and persevere with a responsive and developmental approach to CCoPs that seeks ways to deeply include families' and children's knowledge into the work of meaning-making and action for social justice. This is an approach that, following Long and colleagues (2016) recognizes and blurs power relationships among group members and recognizes all knowledge as valuable. Given the influence of Ruby Payne, this work can be very challenging and must incorporate ongoing reflection by all members, including teachers and administrators.

(6) Recognize the depth to which cultural and other differences may influence families' and other individuals' participation in CCoPs (Hodges, 1998) and work together to 
promote inclusivity as well as a respect for difference, using Deleuze and Guattari's (1987) ideas where possible. This is a strategic departure from placing words in families' mouths in order to meet accountability targets.

(7) Choose carefully the local norms to study as foci for CCoP discussions. A chapter that might be useful is by Nicholson, Grant-Groves, Bauer, and Woolley (2015). This chapter centers a case study in order to show readers how a new approach to readiness in a high-poverty community might occur by shifting to a social justice approach. It could be made into an audio or video narrative by group members and presented to a $\mathrm{CCoP}$ for discussion. This would provide an interpretive text for $\mathrm{CCoP}$ members to examine and discuss in relation to their local context and the topic of readiness would map well onto local concerns. Given the needs of these communities, "culture" and "poverty" are clearly important topics of discussion. Addressing these ideas would first involve recognizing that people affected by poverty are resilient and can indeed discuss honestly meanings of poverty within the community; they no longer need to be protected, shamed, and silenced. The specific questions, concerns, and interests of lowincome children and families should be included and guide CCoP work. This is especially important because, as my family data showed, families had significant anxieties around UPK.

(8) While a fluid framework like Deleuze and Guattari's (1987) is very useful for seeing opportunities for critical dialogue and agency that are often missed, it is also important to bring structure and careful planning to $\mathrm{CCoP}$ meetings while allowing for flexible dialogue. Depending on the group, agendas and conversation protocols (for example for analyzing the case described in point [5] above) may enhance CCoP functioning (Kuh, 2012).

(9) Specific family contexts at the schools should be considered when thinking about how families and children might be included in CCoPs. For example, when fathers are away from the home during the week fracking, childcare at meetings is essential. When fingerprinting and classes are required of families before they might volunteer at school, these services/screenings need to be brought directly to the local schools, and/or the policy might be seriously reconsidered. Examples of family agency in national contexts (Rogers \& O'Brien, 2011) and specifically rural, Appalachian contexts (Gliner, 2012) related to local concerns such as health and safety might provide prompts to move the conversation from only neoliberal concerns like narrow academic skills, deficit-moralism, and child and parent behaviors to instead promoting vigorous discussion and action in and through CCoPs.

(10) Community programs like Young 'Uns that induct children and families into the school community from birth are very effective, based on anecdotal data and might be a strong route to the expansion and formulation of CCoPs. This allows the advantage of families and children becoming more familiar with the P-5 school before becoming part of more formalized groups.

The pragmatic approach to CCoPs outlined in this paper should not deflect from developing systematic efforts to attract, hire, and retain administrators and educators from Appalachian, low income, and/or minority backgrounds and critical educational program who would bring social justice leadership to UPK and elementary school settings. However, in the meantime rather than continue to maintain the status quo of a consumer-oriented, standardized educational culture thinly 
veiled by the term "universal," UPK and other forms of pre-kindergarten might afford diverse families, children, and their educators better opportunities to experience and contribute to educational equity. While there is no easy fix, this study contributes suggestions for action towards more welcoming and supportive environments that shift community dynamics for families traditionally marginalized in early education through CCoPs. 
Becoming Critical Communities of Practice in Pre-Kindergarten

\section{References}

Apple, M. W., \& Beane, J. (2007). Democratic schools: Lessons in powerful education, $2^{\text {nd }}$ ed. Portsmouth, NH: Heinemann.

Barnett, W. S. (2013). Getting the facts right on pre-k and the president's pre-k proposal. New Brunswick, NJ: NIEER.

Barnett, W. S., et al. (2015). The state of preschool 2015: State preschool yearbook. New Brunswick, NJ: National Institute for Early Education Research.

Barnett, W. S., Carolan, M. E., Fitzgerald, J., \& Squires, J. H. (2011). The state of preschool 2011: State preschool yearbook. New Brunswick, NJ: National Institute for Early Education Research.

Barnett, W. S., Carolan, M. E., Squires, J. H., \& Clarke Brown, K. (2013). The state of preschool 2013: State preschool yearbook. New Brunswick, NJ: NIEER.

Barnett, W. S., Robin, K. B., Hustedt, J. T., \& Schulman, K. L. (2003). The state of preschool 2003: State preschool yearbook. New Brunswick, NJ: NIEER.

Billings, D. B., Norman, G., \& Ledford, K. (2000). Back talk from Appalachia: Confronting stereotypes. Lexington: University of Kentucky Press.

Bomer, R., Dworin, J. E., May, L., \& Semingson, P. (2008). Miseducating teachers about the poor: A critical analysis of Ruby Payne's claims about poverty. Teachers College Record, 110(12), 2497-2531.

Brown, C. P., \& Lee, J. (2012). How to teach to the child when the stakes are high: Examples of implementing developmentally appropriate and culturally relevant practices in kindergarten. Journal of Early Childhood Teacher Education, 33(4), 322-348.

Bushouse, B. K. (2010). Universal preschool: Policy change, stability, and the Pew Charitable Trusts. Albany, NY: SUNY Press.

Buysse, V. L., Sparkman, K. L., \& Wesley, P. W. (2003). Communities of practice: connecting what we do with what we know. Exceptional Children, 63(3), 263-277.

Cavalluzzo, L., Clinton, Y., Holian, L., Marr, L., \& Taylor, L. (2009). West Virginia's Progress Toward Universal Prekindergarten. Washington, DC: U.S. Department of Education, Institute of Education Sciences, National Center for Education Evaluation and Regional Assistance, Regional Educational Laboratory Appalachia. Retrieved from http://ies.ed.gov/ncee/edlabs.

Claxton, G., \& Carr, M. (2004). A framework for teaching learning: the dynamics of disposition. Early Years, 24(1), 87-97. 
Cooper, C. W. (2009). Performing cultural work in demographically changing schools: Implications for expanding transformative leadership frameworks. Educational Administration Quarterly, 45(5), 694-724.

Cooper, C. W., Riehl, C. J., \& Hasan, A. L. (2010). Leading and learning with diverse families in schools: Critical epistemology amid communities of practice. Journal of School Leadership, 20, 758-788.

Copple, C. \& Bredekamp, S. (2010). Developmentally appropriate practice in early childhood programs serving children birth thru age $8,3^{\text {rd }}$ ed. Markham, ON: Pembroke.

Crozier, G., \& Vincent, C. (2005). Activating participation: Parents and teachers working towards partnership. Stoke-on-Trent, UK: Trentham.

de la Torre, et. al. (Eds.) (2011). Transforming Public Education: Pathway to a Pre-K-12 Future. Washington, DC.: Pew Center on the States.

Deleuze, G., \& Guattari, F. (1987). A thousand plateaus: Capitalism and schizophrenia. Minneapolis, MN: University of Minnesota Press.

Delgado-Gaitan, C. (2001). The power of community: Mobilizing for family and schooling. Lanham, MD: Rowman \& Littlefield.

Delpit, L. (2006). Other people's children: Cultural conflict in the classroom. New York: New Press.

Derman-Sparks, L., \& Ramsey, P. G. (2006). What if all the kids are white? Anti-bias multicultural education with young children and families. New York: Teachers College Press.

Emerson, R. M., Fretz, R. I., \& Shaw, L. L. (2011). Writing ethnographic fieldnotes, $2^{\text {nd }}$ ed. Chicago: University of Chicago Press.

Fleer, M. (2003). Early childhood education as an evolving 'Community of Practice' or as lived 'Social Reproduction': researching the 'taken-for-granted'. Contemporary Issues in Early Childhood, 4(1), 64-79.

Fuller, B. (2007). Standardized childhood: The political and cultural struggle over early education. Stanford, CA: Stanford University Press.

Gliner, B. (2012). Schools that change communities [Motion Picture]. U.S.: American Public Television.

Goldstein, L. S. (2008). Kindergarten teachers making "street level" education policy in the wake of No Child Left Behind. Early Education and Development, 19(3), 448-478. 
Becoming Critical Communities of Practice in Pre-Kindergarten

Gormley, W. T. (2005). The Universal Pre-K bandwagon. The Phi Delta Kappan, 87(3), 246249.

Gormley, W. T., \& Gayer, T. (2005). Promoting school readiness in Oklahoma: An evaluation of Tulsa's Pre-K Program. The Journal of Human Resources, 3, 533-558.

Gormley, W. T., Phillips, D., \& Gayer, T. (2008). Preschool programs can boost school readiness. Science, 320(27): 1723-1724.

Gorski, P. (2013). Reaching and teaching children in poverty. New York: Teachers College Press.

Graue, M. E., \& Sherfinski, M. (2011). The view from the lighted schoolhouse: Conceptualizing home-school relations in a class size reduction reform. American Journal of Education, 117(2), 1-31.

Hands, C. (2014). Somewhere between a possibility and a pipe dream: District-level leadership that promotes family inclusion and engagement in education. Journal of Family Diversity in Education, 1(2), 88-111.

Henry, G. T., \& Rickman, D. K. (2007). Do peers influence children's skill development in preschool? Economics of Education Review, 26(1), 100-112.

Hodges, D. C. (1998). Participation as dis-identification with/in a community of practice. Mind, Culture, and Activity, 5(4), 272-290.

Hong, S. (2011). A chord of three strands: A new approach to parent engagement in schools. Cambridge, MA: Harvard University Press.

Howley, A., Howley, C. B., Howley, M., \& Howley, C. (2014). Saving the children of the poor in rural schools. In C. B. Howley, A. Howley, \& J. D. Johnson (Eds.), Dynamics of social class, race, and place in rural education (pp. 139-164). Charlotte, NC: Information Age.

Jozkowiak, M. M., Cahill, B. J., \& Theilheimer, R. (2016). Continuity in children's worlds: Choices and consequences for early childhood settings. New York: Teachers College Press.

Kuh, L. P. (2012). Promoting communities of practice and parallel process in early childhood settings. Journal of Early Childhood Teacher Education, 33, 19-37.

Kvale, S., \& Brinkmann, S. (2014). InterViews: Learning the craft of qualitative research interviewing, $3^{\text {rd }}$ ed. Thousand Oaks, CA: Sage.

Ladson-Billings, G. (1995). "But that's just good teaching!" The case for culturally relevant pedagogy. Theory into Practice, 34(3), 159-165. 
Lave, J., \& Wenger, E. (1991). Situated learning: Legitimate peripheral participation. Cambridge, UK: Cambridge University Press.

Lawrence-Lightfoot, S. (2004). The essential conversation: What teachers and parents can learn from each other. New York: Ballantine.

Li, G. (2010). Social class, culture, and "good parenting": Voices of low-SES families. In M. Miller-Marsh and T. Turner-Vorbeck (Eds.), (Mis)understanding families: Learning from real families in our schools (pp. 162-178). New York: Teachers College Press.

Long, S., Souto-Manning, M., \& Vasquez, V. M. (2016). Courageous leadership in early childhood education: Taking a stand for social justice. New York: Teachers College Press.

MacNaughton, G. (1997). Praxis and the gaze in early childhood curriculum. Gender and Education, 9(3), 117-126.

Mashburn, A. J., Pianta, R. C., Downer, J. T., \& Pianta, R.C. (2009). Peer effects on children's language achievement during prekindergarten. Child Development, 80(3), 686-702.

McCabe, L. A., \& Sipple, J. W. (2011). Colliding worlds: Practical and political tensions of prekindergarten implementation in public schools. Educational Policy, 25, e1-e26.

Miller, J. L. (2005). Sounds of silence breaking: Women, autobiography, curriculum. New York: Peter Lang.

Myers, M. (2016). Understanding family involvement: Race, class, and family life in a rural Black community. In S. Long, M. Souto-Manning, and V. M. Vasquez (Eds.), Courageous leadership in early childhood education: Taking a stand for social justice (pp. 80-90). New York: Teachers College Press.

Nicholson, J., Grant-Groves, M., Bauer, A., \& Wooley, R. (2015). Inserting postmodern epistemological perspectives into discourse on readiness: Privileging assets, capacity building, and diversity to increase equity. In J. M. Iorio and W. Parnell (Eds.), Rethinking readiness in early childhood education: Implications for policy and practice. New York: Palgrave Macmillan.

Oakes, J., Rogers, J., \& Lipton, M. (2006). Learning power: Organizing for education and justice. New York: Teachers College Press.

Payne, R. K. (2013). A framework for understanding poverty: A cognitive approach, $5^{\text {th }}$ ed. Highlands, TX: Aha! Process.

Pollock, M. (2005). Colormute: Race talk dilemmas in an American school. Princeton, NJ: Princeton University Press. 
Ramsey, P. G. (2004). Teaching and learning in a diverse world, $3^{\text {rd }}$ ed. New York: Teachers College Press.

Reay, D. \& Ball, S. (1997). 'Spoilt for choice': The working classes and educational markets. Oxford Review of Education, 23(1), 89-101.

Rogers, R., \& O’Brien, D. (2011). In C. Compton-Lilly and S. Greene (Eds.), Bedtime stories and book reports: Connecting parent involvement and family literacy (pp. 52-64). New York: Teachers College Press.

Saltmarsh, S., \& Davies, C. (2010). Risky childhoods in uncertain times. Contemporary Issues in Early Childhood, 11(3), 230-233.

Schulman, K., \& Barnett, W. S. (2005, March). The benefits of pre-kindergarten for middleincome children. National Institute for Early Education Research (NIEER), 1-14.

Sherfinski, M. (2013). Class and parents' agency in West Virginia: Between choices and rights. Education Policy Analysis Archives, 21(78), 1-35.

Sherfinski, M., Weekley, B. S., \& Mathew, S. (2015). Reconceptualising advocacy: Creating inclusive education in U.S. universal pre-kindergarten. International Journal of Inclusive Education, 19(12), 1213-1228.

Sherfinski, M., Weekley, B. S., \& Slocum, A. (2016). After Arthurdale: Place-based education and early childhood in West Virginia. Journal of Curriculum \& Pedagogy, 13(2), 164183.

Silin, J. G. (1995). Sex, death and the education of children: Our passion for ignorance in the age of AIDS. New York, NY: Teachers College Press.

Sleeter, C. E., \& Grant, C. A. (1988). Making choices for multicultural education: Five approaches to race, class, and gender. New York: Macmillan.

Snell, P. (2011). Parents defining parent involvement. In C. Compton-Lilly and S. Greene (Eds.), Bedtime stories and book reports: Connecting parent involvement and family literacy (pp. 29-38). New York: Teachers College Press.

Stack, Jr., S. (2016). The Arthurdale community school: Education and reform in DepressionEra Appalachia. Lexington: University of Kentucky Press.

Stake, R. E. (2005). Multiple case study analysis. New York: Guilford Press.

U. S. Census (2010). Retrieved from http://www.census.gov/2010census/

Wenger, E. (2000). Communities of practice: Learning, meaning and identity. Cambridge, UK: Cambridge University Press. 
West Virginia Board of Education (WVBOE). (2014). West Virginia's Universal Access to a Quality Early Education System (Policy 2525) Reenactment.

West Virginia Board of Education (WVBOE). (2015). Early Learning Standards. Retrieved from http://apps.sos.wv.gov/adlaw/csr/readfile.aspx?DocId=26880\&Format=PDF

West Virginia Department of Education (WVDOE). (2015a). "West Virginia School Readiness Profile." Retrieved from https://wvde.state.wv.us/ready-set-go/doc/2015-schoolreadiness-profile.pdf

West Virginia Department of Education (WVDOE). (2015b). "Zoom School Information." Retrieved from http://zoomwv.k12.wv.us/Dashboard/portalHome.jsp 